\title{
Development of HIV prevention motivation model for promoting healthy behavioral changes in conscripts of the ninth of battalion infantry
}

\author{
Orawan Julawong, Wanarat Srikanok \\ The Royal Thai Army Nursing College, Bangkok, Thailand \\ Correspondence: Orawan Julawong. Address: 499/506 Sriayuthaya Rd, Payatai, Bangkok, Thailand. Email: \\ Orawan3@yahoo.com.
}

Received: February 25, 2013

DOI : $10.5430 /$ jnep.v4n1p18
Accepted: April 8, $2013 \quad$ Online Published: May 29, 2013

URL: http://dx.doi.org/10.5430/jnep.v4n1p18

\section{Abstract}

Purpose: To develop an HIV prevention motivation model for promoting healthy behaviors changes in Thai Army conscripts of the ninth battalion infantry. Design: Design combined quantitative and qualitative methods.

Methods: The three phases: Phase I, data collection, Phase II, Focus Groups, and Phase III, Model Development. Phase I, used stratified random sampling from 387 conscripts who completed a questionnaire about behaviors related to HIV infection. Results of this phase were used to develop a Motivation for Preventing HIV Infection questionnaire and a Semi-Structured Interview Guide. Conscripts were divided into 3 groups based on behaviors, (1) risky behaviors (2) alternatively risky to healthy behaviors, and (3) healthy behaviors. Conscripts completed the motivation for preventing HIV infection questionnaire. Phase II, was used to collect data from 8 conscripts based on their behaviors associated with HIV infection. Focus groups with their family members, close friends, and commanders were also conducted. Phase III, combined the results of phase I and II to develop The Model. Data Analysis: mean, SD, correlation, regression, and content analysis were used.

Results: The study revealed positively significant relationship between availability of consulting wife or girlfriend when having stress, hobby, availability of consulting close friend when having stress, experience viewing AIDS patients, army policy, influencing of commander and motivation for preventing HIV infection $(p<0.05)$. Regression analysis also revealed that these variables account for $7.0 \%$ of the motivation variance related to behavior change in prevention of HIV infection $(p<0.05)$.

Conclusions: The study findings were used to develop the model which focused perception of severity, self-efficacy, life-expectation, and social support.

\section{Key words}

Prevention motivation model, Motivation, Health behavioral changes, Conscripts

\section{Background}

Human immunodeficiency virus (HIV) has spread to every country in the world. A 2010 UNAIDS report on the world epidemic of AIDS \& HIV reported there are 34 million people worldwide living with HIV/AIDS. Approximately 2.7 
million are newly infected with HIV ${ }^{[1]}$. Puberty, with age ranges between 15 and 24 years is the most risky period for the likelihood to catch HIV infection ${ }^{[2]}$. Heterosexual contact is the main mode of transmission of HIV. Unsafe sex has spread the disease to young generations resulting in rapidly spreading STDs ${ }^{[3]}$, and found the most risky areas for STDs is in South East Asia ${ }^{[4]}$.

In Thailand, it is estimated that 530,000 people have been infected with HIV. The prevalence of HIV infection is $1.3 \%{ }^{[1]}$. One out of 5 of those newly infected with HIV was caused by unsafe heterosexual activities ${ }^{[5]}$. The youths' ages ranged from 15-22 years. This high rate of HIV infection is largely due to a lack of concern about the severity of the disease ${ }^{[3]}$.

Thai army conscripts are one of those most at risk for HIV infection, and continue to experience a high rate of contracting the disease. Although the number of new HIV infections has decreased in the past few years, the ratio of new HIV infections in younger populations like Thai conscripts is still high. Lack of concern about the severity of the disease in young adults may take on an important role about the infection ${ }^{[6]}$. Uniformed services are highly susceptible to sexually transmitted infections (STIs), mainly because of their work environment, mobility, age, and other facilitating factors exposing them to a higher risk of HIV infection.

Factors that put conscripts at risk of HIV infection is by engaging in unsafe sex with commercial sex workers is stress from military training ${ }^{[7]}$. Several surveys on behaviors in conscripts found that the conscripts had high risk for HIV infection ${ }^{[8-11]}$. According to Celentano and colleague ${ }^{[12]}$, the conscripts had to adjust to a new environment and army rules. They also release stress by consumption of alcohol drinking and patronizing brothels. This finding was congruent with the study of Bhusal ${ }^{[13]}$, survey behaviors of 200 conscripts, revealing that almost $50 \%$ of the conscripts have never used condoms and that drinking alcohol was an important issue that triggered unsafe sexual activities; which were consistent with several previous studies ${ }^{[14,15]}$. The survey of conscripts' behaviors related to HIV infection, revealed that most conscripts have first sex at age 19, with at least 2 partners. Most conscripts used condom inconsistently. The more frequent the sexual activities, the less they use condoms. $85 \%$ of conscripts experience using alcohol. $50 \%$ of those, after drinking alcohol, go to a brothel ${ }^{[16]}$. Workplace policy can be another important issue that influences motivation of health protection. A better understanding of the problem by administrators in the workplace environment can motivate individuals to alternate from risky to healthy behaviors ${ }^{[17]}$.

Friends \& peer groups also play an important role in the decision of whether or not to engage in risky behaviors. Most conscripts came from remote areas to be trained in the army. They are separated from family and lack familial \& emotional support when stressed by work. Several previous studies revealed that peer groups took control to convince friends to engage in, or avoid risky behaviors ${ }^{[18-20]}$. In addition, the conscripts' age fell between 18-30 which can be a factor that influences their protection motivation, or displaying risky behaviors through sexual desire, decision making or intention to use condoms ${ }^{[21-23]}$.

HIV/AIDS is related to behaviors which are difficult to change. Protection motivation is an important issue to drive decision making about healthy behaviors. It is important to encourage changing risky to healthy behaviors in the conscripts. Protection motivation is one of the important factors that focus on cognitive thinking processes before individuals make a decision whether or not to engage in healthy or risky behaviors. Therefore, this study will answer the question of how to change risky behaviors into healthy behaviors of these particular groups.

The theoretical basis for this study was derived from Roger's Protection Motivation Theory ${ }^{[24]}$ and Trans-theoretical model: Stage of Change ${ }^{[25]}$. The Protection Motivation Theory focuses on the cognitive process of motivation in preventing risky behaviors which focus on threat appraisal, coping appraisal, and response, which can be an effective and ineffective response. Threat appraisal is the individual perception of severity and the impact of the threat that leads to positive outcome expectancies or negative outcome expectancies, while coping appraisal is the appraisal of resources or other supports. The resources are viewed as family, friends, colleagues, equipment or financial supports. When an individual evaluates the severity of the threat, having self-efficacy to deal with the threat, and having adequate supports, 
they will intend to change from risky to healthy behaviors and be able to maintain healthy behaviors. On the other hand, individuals who are not concerned with the severity of the threat, having low self-efficacy, and lack of supports, will have no motivation to protect their health, or will continue engaging in risky behaviors. Trans-theoretical model: Stage of Change also focuses on cognitive process of behavior change that indicates the step of change and influenced variables in each different stage.

In this study, behaviors related to HIV prevention in different stages of change were divided into 3 groups: (1) Healthy behaviors, (2) Alternatively risky to healthy behaviors, and (3) Risky behaviors. The motivation in preventing HIV infection was viewed as the process of motivation including perception of severity of the disease, self-efficacy, lifeexpectation, and social support. Selected factors were viewed as the factors influencing motivation processes leading to behaviors related to HIV infection including character of the army training, army policy, influence of commanders, friends, relationships of family members and other supports such as availability of consulting their love ones and closed friends.

By understanding patterns of motivation for promoting changes to behaviors to prevent HIV infection and understanding their involvement, the study findings will provide guidance to develop a model of motivation for promoting changing behaviors to prevent HIV infection in Thai army conscripts in the Ninth of Regiment.

\section{Research questions}

(1) What are the behaviors related to HIV infection in Thai army conscripts of the ninth battalion infantry?

(2) What is the motivation of HIV prevention in Thai army conscripts of the ninth battalion infantry?

(3) What factors are related to ninth battalion infantry Thai Army conscripts' motivation for HIV prevention?

(4) How is the model for motivating changing behaviors in Thai army conscripts of the ninth battalion infantry, to prevent HIV infection, developed?

The purpose of the study was to develop a model of motivation for promoting changing behaviors to prevent HIV infection which includes subtypes, (i) level of motivation for preventing HIV infection, and (ii) factors that influence motivation for preventing HIV infection.

\section{Research design}

The study used a triangulation method, which combined the quantitative and qualitative methods.

\section{Methods}

There are three phases: Phase I, II (developing the model), phase I, data collection included (1) 387 conscripts were selected by using stratified random sampling technique, and completed a questionnaire about behaviors related to HIV infection. The result of this phase was used to develop the Motivation for Preventing HIV infection questionnaire, and Semi-Structured Interview Guide, and to divide the conscripts into 3 separated groups based on their behaviors related to HIV infection including 1) healthy behaviors 2) alternatively risky to healthy behaviors, and 3) risky behaviors. (2) 387 conscripts completed the motivation for preventing HIV infection questionnaire and other related factors. Phase II, Focus groups were used to collect data separately from 8 conscripts in each group based on their behaviors associated with HIV infection. Each focus group took place in a private room and lasted approximately 50-65 minutes. Also, separate in-depth interviews with their family members, close friends, and commanders were conducted. The in-depth interview for the subjects' family members and their close friends were conducted after receiving permission from the subjects who also provided the names and telephone numbers of those they selected. The researcher contacted the family members by phone to ask for permission and made appointments for the in-depth interview at times that were convenient for them. Each 
interview lasted approximately 45-60 minutes. For the commander, the researcher selected three commanders by random sampling. The three were squad commanders were conscripts were trained and taught army discipline and were in charge of the conscripts' personal life while the conscripts in at the base. Each of the commanders' interviews took place in the private room of the army base and lasted about 45 minutes.

Phase III, the results of phase I and II were integrated to develop the Motivation Model for Promoting Changing Behaviors to Prevent HIV Infection

\subsection{Instruments}

The instruments that were used in the study were: (A) Demographic Data Form, (B) The Survey of Health Behaviors related to HIV Infection, (C) Motivation for Preventing HIV infection, and (D) Semi-Structured Interview Guide

\section{The survey of health behaviors related to $\mathrm{HIV}$ infection}

The survey of health behaviors related to HIV infection, developed by the researcher, shows reliability was 0.74 . Content validity was established by having a panel of experts rates the items. The content validity index was calculated for each item of the questionnaires. Each item of the questionnaires was agreed upon by the experts with an index of congruence (IOC) $p>0.5$, those are the items that have been selected. The questionnaire consisted of 35 items, including (1) daily living, (2) sexual activities, (3) alcohol/drug use. Each item was measured on a 0 through 2 point scale ( $0=$ no such behaviors, $1=$ having those behaviors 2-3 times a month, and 2=having those behaviors more than 3 times a month). A low score on the survey of health behaviors related to HIV infection means the participants have no risky behaviors. A high score means participants have a high frequency of risky behaviors related to HIV infection.

\section{The motivation for preventing HIV infection}

The Motivation for preventing HIV infection was developed by the researcher. The reliability was 0.72 . Content validity was established by having panel of experts rate the items. The content validity index was calculated for each item of the questionnaires. Each item of the questionnaires was agreed by the experts with an index of congruence (IOC) $p>0.5$, those are the items that have been selected. The questionnaire consisted of 37 items, which include 4 content areas (1) Perception of the severity of the disease, (2) Self-Efficacy, (3) Life expectation, and (4) Social Support. Each item was measured on a 1 through 5 -point scale ( 1 = strongly disagree, $5=$ strongly agree). A low score on The Motivation for preventing HIV infection means the participants have low level of motivation in preventing HIV infection. On the other hand, a high score on the Motivation for Preventing HIV Infection means participants have high level of motivation in preventing HIV infection.

\section{Semi-structured interview guide}

The Semi-Structured Interview Guide, developed by the researcher, was composed of open-ended questions. It consisted of nine questions as a guideline for the researcher to ask the participants in order to explore the 4 main concepts of motivation in preventing HIV infection and its related factors, the strategies to avoid risky behaviors. Content validity of the Semi-Structural Interview Guide was established by three experts. For each of the nine questions, when two out of three validators were in agreement, those questions were accepted.

\subsection{Protection of human subjects}

The research proposal was submitted for approval. In keeping with ethical requirements for use of humans in research, all subjects signed Informed Consent Forms before data collection. A subject number or code was then assigned to each participant. This code was used to identify potential subjects with their data. Codes of the potential subjects were made available only to the investigator. All information was kept confidential and secure. Participation in the study was entirely voluntary. Subjects in both the quantitative and qualitative portion were informed by the researcher of all the details of the study's purposes, potential risks and benefits of participation, and their rights to withdraw from the study at anytime without any effect on their job. They were also informed of the ways in which data would be gathered, and the ways in 
which privacy and confidentiality would be maintained. Informed Consent Forms were used with the participants who participated in quantitative and qualitative methods of data collection separately. For the participants' families and close friends, the researcher only contacted those for whom the subjects gave the researcher permission.

\subsection{Data analysis}

Using SPSS, quantitative data were coded, and then entered into a database for analysis.

(1) Descriptive statistics were used to analyze the demographic data

(2) Pearson Product Moment Correlation Coefficient allowed the research to state mathematically the relationship that existed between motivation for preventing HIV infection and selected factors

(3) Multiple regression analysis was performed to test the selected factors that explain most of the variance of the motivation for preventing HIV infection.

Qualitative data were developed by using content analysis based on Johnson and LaMontague ${ }^{[26]}$ which consists of six steps. The six steps include (1) data preparation for analysis. Verbatim transcription of participant interviews using the Semi -Structured Interview Guide and field notes were added as needed, (2) reading interview transcripts and making notes capturing overall nature of the participants' responses by the investigator, (3) identifying units of analysis, (4) developing tentative categories based on the motivation for preventing HIV infection, (5) refining the categories, and (6) confirming category integrity. To confirm the rigorous validity of the findings, the participants who participated in the in-depth interview received a follow-up interview to reflect the accuracy of the qualitative study findings.

\section{Results}

\subsection{Quantitative findings}

Average age of the subjects was 22 years; 99.22\% Buddhist. 66.12\% came from north east Thailand. 71.06\% were single. Average monthly income was $\$ 228$. Household monthly income was $\$ 380.20 .16 \%$ had experience with AIDS patients.

The overall mean scores of health behaviors was 0.95 and standard deviation of 0.57 . This suggests the majority of subjects have no to slightly low HIV risky behaviors. Looking at risky health behaviors related to HIV infection, it was found that alcohol/ drug use has highest scores, followed by daily living, and sexual activities ( $\bar{x}=1.34,0.93$, and 0.64 ), respectively (see Table 1).

Table 1. Health Behaviors Related HIV Infection (N=387)

\begin{tabular}{lll}
\hline Health Behaviors & $\bar{x}$ & SD \\
\hline 1. Daily Living & 0.93 & 0.35 \\
2. Sexual Activities & 0.64 & 0.63 \\
3.Alcohol/Drug Use & 1.34 & 0.60 \\
Total & 0.95 & 0.57 \\
\hline
\end{tabular}

As shown by table 2, the overall mean scores of motivation for preventing HIV infection was in moderate level. $(\bar{x}=3.69$, $\mathrm{SD}=1.19$ ). This suggested that the majority of the subjects have moderate motivation in preventing HIV infection. It was found that perception of severity of the disease had highest mean scores ( $\bar{x}=4.05, \mathrm{SD}=0.98$ ) following by life-expectation, self-efficacy, and social support $(\bar{x}=3.94, \mathrm{SD}=1.25, \bar{x}=3.54, \mathrm{SD}=1.06$, and $\bar{x}=3.33$, SD=1.18) respectively. 
Table 2. Overall and each part of Motivation for Preventing HIV Infection

\begin{tabular}{lll}
\hline \multirow{2}{*}{ Motivation } & Total & \\
\cline { 2 - 3 } & $\bar{x}$ & SD \\
\hline Perception of Severity of the Disease & 4.05 & 0.98 \\
Self-Efficacy & 3.54 & 1.06 \\
Life- Expectation & 3.94 & 1.25 \\
Social Support & 3.33 & 1.18 \\
Total & 3.69 & 1.19 \\
\hline
\end{tabular}

The overall correlation between selected factors and motivation for preventing HIV infection, revealed a positively significant relationship among availability of consulting a wife, girlfriend, parents, or close friend when having stress, hobbies, experience viewing AIDS patients, army policy, influence of the commander, region of origin, character of the army training, and motivation for preventing HIV infection $(\mathrm{p}<0.05)$. The study also found that the influence of friends, and age, had a negative significant relationship with each part of the conscripts' motivation for preventing HIV infection. There was negative significant relationship between the influence of friends and life expectation. Age also had a negative significant relationship with the perception of the severity of the disease. However, an overall correlation between the influence of friends, age, and motivation for preventing HIV infection revealed an insignificant negative relationship (see Table 3).

Table 3. Correlations between selected Factors and Motivation for Preventing HIV Infection N=387 (P1: Perception of severity of the disease, P2: Self-Efficacy, P3: Life-Expectation, P4: Social Support

\begin{tabular}{|c|c|c|c|c|c|}
\hline \multirow{2}{*}{ Selected Factors } & \multicolumn{5}{|c|}{ Correlation $\mathrm{r}$} \\
\hline & P1 & $\mathbf{P 2}$ & P3 & P4 & Total \\
\hline Availability of consulting wife or girlfriends when having stress & $0.491 *$ & $0.453 *$ & $0.515^{*}$ & 0.466 & $0.654 *$ \\
\hline Hobby & $0.637 *$ & $0.477 *$ & $0.583 *$ & $0.636 *$ & $0.616 *$ \\
\hline Availability of consulting close friends when having stress & 0.379 & $0.453 *$ & 0.470 & $0.538 *$ & $0.613 *$ \\
\hline Experience viewing AIDS patients & 0.398 & 0.311 & 0.473 & $0.576 *$ & $0.608 *$ \\
\hline Army policy & $0.492 *$ & $0.728 *$ & $0.448 *$ & $0.635 *$ & $0.606^{*}$ \\
\hline Influencing of commanders & $0.700 *$ & $0.720 *$ & 0.260 & 0.244 & $0.602 *$ \\
\hline Region of origin & $0.446 *$ & $0.490 *$ & $0.496 *$ & 0.504 & $0.596 *$ \\
\hline Availability of consulting parents when having stress & $0.506 *$ & $0.437 *$ & $0.504 *$ & $0.592 *$ & $0.594 *$ \\
\hline Character of the army training & 0.168 & -0.152 & 0.131 & $0.306^{*}$ & $0.463 *$ \\
\hline 10. Availability of consulting commanders & $0.569 *$ & $0.522 *$ & $0.629 *$ & $0.569 *$ & 0.424 \\
\hline 11. Influencing of friends & 0.196 & -0.352 & $-0.716^{*}$ & $0.304 *$ & -0.376 \\
\hline 12. Income & 0.138 & $0.314 *$ & -0.186 & 0.222 & 0.168 \\
\hline 13. Age & $-0.448 *$ & -0.197 & 0.059 & 0.011 & -0.168 \\
\hline
\end{tabular}

Note: * Correlation is significant at the 0.05 level (two-tailed)

Table 4. Multiple Regression Analysis of Motivation for preventing HIV infection on Predictor Variables of selected factors

\begin{tabular}{|c|c|c|c|c|}
\hline Variables & Beta & Constant & $\overline{\mathbf{R}^{2}}$ & SE \\
\hline Availability of consulting wife/ girl friends when having stress (a) & 0.33 & \multirow{6}{*}{6.44} & \multirow{6}{*}{0.07} & \multirow{6}{*}{0.63} \\
\hline Hobby (b) & 0.23 & & & \\
\hline Availability of consulting closefriends when having stress (c) & 0.21 & & & \\
\hline Experience viewing AIDS patients (d) & 0.22 & & & \\
\hline Influencing of commanders (e) & 0.19 & & & \\
\hline Army policy (f) & 0.20 & & & \\
\hline
\end{tabular}

Based on the strength of correlation, forward regression analysis was conducted to explore the predictor of motivation for preventing HIV infection. The results are presented in Table 4. Together, availability of consulting wife/ girl friends when 
having stress, hobby, availability of consulting close friends when having stress, experience viewing AIDS patients, influencing of commanders, and army policy account for $7 \%\left(\mathrm{R}^{2}=0.70\right)$ of the variance of motivation for preventing HIV infection significantly $(p<0.05)$ with developed regression equation as follow:

$$
Y=0.33 a+0.23 b+0.21 c+0.22 d+0.19 e+0.20 f
$$

\subsection{Qualitative findings}

The study samples were Thai army conscripts who were selected from the participants in phase I. The qualitative data analysis was conducted in two stages: analysis of demographic data and content analysis of the focus groups and the in-depth interview data.

The qualitative findings described the meaning of 4 main content areas of motivation for preventing HIV infection. The findings resulted from 3 focus groups with 8 conscripts in each group based on their behaviors associated with HIV infection including (1) Healthy behaviors, (2) Alternatively risky to healthy behaviors, and (3) Risky behaviors, and also separate focus groups with their family members, \& close friends. In-depth interviews were performed with their 3 commanders individually.

\subsection{Demographic characteristics}

The average age of the healthy behaviors group was 21.40 years, 21.62 years for the alternatively risky to healthy behaviors group, and 21.29 years for the risky behaviors group. For marital status, most of the healthy behaviors group and the alternatively risky behaviors group were married. For the risky behaviors group, most were single. All subjects in the three groups were Buddhist. The majority of the subjects in the three groups received similar amounts of household income which averaged of 25,000 bahts (\$862) for the healthy behaviors group, 24,530 bahts (\$845) for the alternatively risky to healthy behaviors group, and 20,010 bahts (\$690) for the risky behaviors group. For the region of origin, most of the subjects in the three groups came from northeastern part of Thailand.

\subsection{Healthy behavior group}

\section{Perception of severity of the disease}

Most of the participants perceived they have basic knowledge of AIDS, prevention of HIV infection, and the impact of the disease. They indicated concern for the severity of the disease, and expressed fear of being infected by the disease. Thus, the majority of the participants often searched for current HIV information. They stated:

"I scare to be infected of HIV...I used to watch TV and see the impact of the disease to whoever got infected......miserably"

"I am curious to join wherever they have campaign for preventing HIV infection.....I want to know to protect myself and my love ones"

\section{Self-efficacy}

Most of the participants are able to control themselves when their friends are trying to persuade them to be involved in risky unsafe activities. They employ various strategies to avoid risky behaviors, such as keeping their loved ones' pictures in their wallets where they can view it frequently. When a risky situation arises, they always look at those pictures which remind them not to be involved in unsafe activities. Additionally, they are reminded not to spend money for those activities. Here are some of their responses:

"I always think about my wife, my kids, and my parents when I am around with friends involving risky behaviors...and I excuse myself away from that kind of activities"

"I keep my love ones' pictures in my wallet all times incase I accidently in the risky situation..I will see those pictures and not engage in the unsafe behaviors” 


\section{Life-expectation}

The majority of the participants have life -expectations, and have planed for their future after completing their obligation to the army. Some will get a job, others will get married and/or decide to take care of their parents, and work closed by their home town. Here are some of their responses:

"I try to do the best I can while I am trained in the army. After I finish, I will go back to my home town and take good care of my parents"

"I miss my family...I like to have a good future for them ...I will apply for a job near by my home town".... "My family expect me to be the head of family....they all depend on me...I won't be them disappointed"

\section{Social support}

Most of the participants have good relationships with other family members. When they are stressed, they often talk with family members. Moreover, they have their girl friends/ wife to give them encouragement when they feel down. They stated:

"I love my family ...I don't want them disappointed if I engage to HIV risky behaviors"

"When I have stress, I always have my family listen and support me..even through the phone call”

"When I have vacation of training, I came back home immediately. I miss my little daughter"

\section{Close friends and families}

Focus groups were conducted with the healthy behavior groups' close friends revealing that most participants in this group posses a humble, calm, and peaceful nature. They always listen and show concern for other's feelings. They prefer not to engage in alcohol consumption, drug use, or violence. Their families also revealed that most participants are responsible, and have good relationships with family members. Family members depend on, and expect them to help the family.

\subsection{Alternatively risky to healthy behavior group}

\section{Perception of severity of the disease}

Most of the participants have basic knowledge of AIDS, prevention of HIV infection, and the impact of the disease. They are scared of the severity of the disease. However, they are unsure whether or not they will be able to control themselves and avoid risky behaviors when influenced by their friends to engage in such behavior. Here some of their expressions:

"I intend to change my risky to healthy behaviors, but I am not sure that I can do that when friends they enjoy and invite me join with them"

"I am scare of AIDS, and afraid of spread the infection to my love one if I got the infection"

\section{Self-efficacy}

The majority of the participants stated they are able to control themselves in avoiding risky behaviors. They also intend to stop risky behaviors. However, when they were around their friends and encouraged to drink alcohol or engage in unsafe sexual behaviors, they feel uncomfortable to refuse. They stated:

"I think I have grown enough to stop risky behaviors that I have been done. When my friends (our gang) ask me to join drinking alcohol and then end up to brothel, I feel uncomfortable to say "no".....I try to refuse, but it did not work... they blame me that I am not a real man. I don't want them to kick me out of the group"

"I try not to join to the group because I know what going end up after we have been drinking...sometimes, I told them that I cannot join because I have to wait for a phone call from my girl or I pretend to be drunk and excuse myself to go to bed because I don't want to go the brothel." 


\section{Life-expectation}

The majority of the participants have life aims and goals. They expect to find jobs after finishing the army. Most want to have their own family and help their parents financially. They stated:

"I want to have my own family and have kids.....I want a job, so I can save money for my future and help my parents"

\section{Social support}

Most participants are concerned about the opinion of their loved ones, if they engage in risky behaviors. They expressed that being in the army had a positive outcome because the discipline and rules limited their free time for engaging in risky behaviors. Also, they were tired from training, and the women in camp did not arouse sexual feelings. They stated:

"I think that is a good thing that I was trained and then feel tired by the end of the day..I just want to relax and sleep."

"When I get bored I play football that provided by the camp instead of going out to the brothel"

\section{Closed friends and families}

Close friends and family members revealed that participants always go back home when they get a vacation from training. During vacation, they spend time with their family and close friends. Their close friends visit them at home and they talk and drink alcohol sometimes. However, when they got drunk, they did not go to the brothel they slept instead.

\subsection{Risky behavior group}

\section{Perception of severity of the disease}

The majority of participants perceived the severity of the disease, but they still thought the disease is far from them and will not affect them soon. Their sexual needs are more important than the fear of disease. They thought sexual activities help them release tension from training. Most participants use alcohol before having unsafe sexual activities. They stated:

"Our sexual desires more than scary the disease.... when we got drunk, we don't scare of the disease"

"I don't think the impact of the disease will affect me soon....so when I get older maybe I quit, but not now"

"I don't like using condom because it made me not happy..in the climax"

\section{Self-efficacy}

Most participants focus on enjoying themselves with drinking and having sexual activities. They are more concerned about having fun than thinking carefully before engaging in risky behaviors. They stated:

"When I want to have sex, I forget everything...I think about the consequences, but very short time in my mind"

"It seems like my sexual desire is more important than anythingels"

\section{Life-expectation}

The majority of participants do not have plans for their future. Most did not know what they will do after finishing the army. Some said they will stay home and have fun with friends. They know that they should plan for their future, but they expressed it is not time yet. They stated:

"Now I have nobody to worry about...no girl friend...no aim in the future"

"For me, I think it is not time for me yet to stop having fun...I think life is valuable when you experience something like this" 


\section{Social support}

Most participants in this group lack love and support from family members. Most come from unhappy families. The most important person for them is their friend(s). Most of their friends also often involve with risky behaviors for HIV. They stated:

"My mom knows what I did...she knows she cannot stop me...she just asks me to use condom”

"When I have vacation from training, I always guff around with my friends having fun, drinking and going to the brothel"

"I don't want to go back home. It is not happy to be at home....in the morning everybody gone for work by the evening they come back, but me...I hang around with my friends and sometimes stay over night at my friends' house”

\section{Close friends and families}

The findings from close friends and their family are consistent with the findings from the participants. Their close friends expressed they like to have fun together drinking, and when got drunk they engage in unsafe sexual activities. Similar to the participants, family information revealed that they thought the participants did not try to improve themselves. Family members found it difficult to tell the participants not to engage risky behaviors because they know it does not work.

\section{Commanders}

Three commanders revealed that friends have a lot of influence over conscripts' behaviors. Army policy has provided various areas for conscripts to relax after training. Also, there are consultants (counselors) available 24 hours a day if conscripts need to express their feelings. However, conscripts prefer talking to friends more than commanders.

\subsection{I ntegration of quantitative findings and qualitative findings}

The results of quantitative and qualitative methods were analyzed and integrated to develop the Model of Motivation for Promoting Changing Behaviors to Prevent HIV Infection (The Model) in the conscripts as follow:

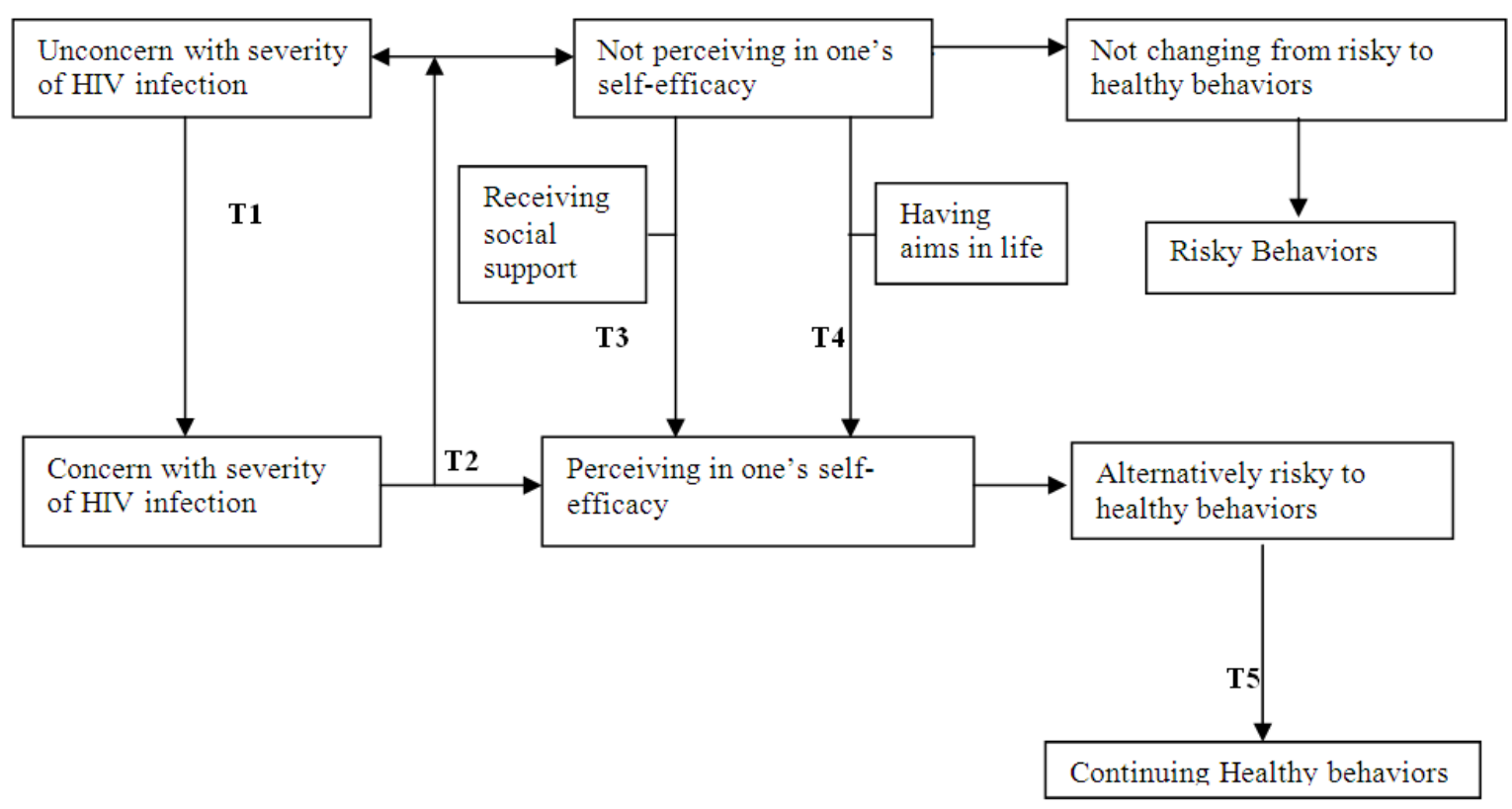

Figure 1. The Motivation for Promoting Changing Behaviors to Prevent HIV Infection in conscripts 
Table 5. Activity Guideline of the Motivation for Promoting Changing Behaviors to Prevent HIV Infection in Conscripts

\begin{tabular}{|c|c|c|c|c|c|}
\hline Phase & concepts & Health education & $\begin{array}{l}\text { Promoting of } \\
\text { participation }\end{array}$ & Army policy & Others \\
\hline $\mathrm{T} 1$ & $\begin{array}{l}\text { Promoting } \\
\text { awareness of the } \\
\text { severity of HIV } \\
\text { infection }\end{array}$ & $\begin{array}{l}\text { From peers, educator, } \\
\text { friends-help-friends } \\
\text { People living with HIV } \\
\text { sharing experiences } \\
\text { DVD } \\
\text { Study visit }\end{array}$ & $\begin{array}{l}\text { Group participation } \\
\text { reflecting the impact } \\
\text { of AIDS on self }\end{array}$ & $\begin{array}{l}\text { Providing handy } \\
\text { and easy access to } \\
\text { HIV information } \\
\text { package, } \\
\text { Reminding every } \\
\text { morning about the } \\
\text { severity of HIV } \\
\text { infection }\end{array}$ & $\begin{array}{l}\text { Screening HIV } \\
\text { testing, STDs } \\
\text { screening }\end{array}$ \\
\hline $\mathrm{T} 2$ & $\begin{array}{l}\text { Creating } \\
\text { Self-Efficacy }\end{array}$ & $\begin{array}{l}\text { Practice skill of reminding } \\
\text { ones' self } \\
\text { Practice refusing to } \\
\text { engaging in risky } \\
\text { behaviors } \\
\text { Practicing the strategies of } \\
\text { facing stress } \\
\text { Alcohol consumption } \\
\text { enhancing HIV risky } \\
\text { behaviors }\end{array}$ & $\begin{array}{l}\text { Encouraging roles of } \\
\text { conscript leaders } \\
\text { Encouraging } \\
\text { self-confidence in } \\
\text { sharing the story that } \\
\text { makes one proud of } \\
\text { themselves (talking) } \\
\text { Writing something to } \\
\text { remind self not to } \\
\text { engage in, display, } \\
\text { debate risky behaviors }\end{array}$ & $\begin{array}{l}\text { Providing rewards } \\
\text { \& supports } \\
\text { Sending letter to the } \\
\text { one who did good } \\
\text { to inform their } \\
\text { families } \\
\text { Showing the movie } \\
\text { that encourage high } \\
\text { self -esteem } \\
\text { monthly }\end{array}$ & \\
\hline T3 & $\begin{array}{l}\text { Encouraging } \\
\text { social support }\end{array}$ & $\begin{array}{l}\text { Practice skill of reminding } \\
\text { friends to avoid risky } \\
\text { behaviors, Dharma } \\
\text { teaching, meditation }\end{array}$ & $\begin{array}{l}\text { Hobby program to } \\
\text { increase income, } \\
\text { friends- help-friends }\end{array}$ & $\begin{array}{l}\text { Saving money for } \\
\text { future, counseling } \\
\text { program for squad, } \\
\text { providing free } \\
\text { condoms, providing } \\
\text { family visit, } \\
\text { providing sport } \\
\text { equipment, } \\
\text { providing chaplain }\end{array}$ & $\begin{array}{l}\text { Provide less } \\
\text { expensive options } \\
\text { such as Skype, etc. to } \\
\text { connect to family }\end{array}$ \\
\hline $\mathrm{T} 4$ & $\begin{array}{l}\text { Promoting } \\
\text { meaningful goals } \\
\text { in Life }\end{array}$ & - & $\begin{array}{l}\text { Creating good life } \\
\text { goals program }\end{array}$ & $\begin{array}{l}\text { Preparing job } \\
\text { training program, } \\
\text { connecting } \\
\text { \&net-working for } \\
\text { jobs for the } \\
\text { conscripts after } \\
\text { army life }\end{array}$ & \\
\hline T5 & $\begin{array}{l}\text { Enhancing } \\
\text { continuing } \\
\text { maintaining } \\
\text { healthy behaviors }\end{array}$ & $\begin{array}{l}\text { Provide educational } \\
\text { program booster every } 3 \\
\text { months }\end{array}$ & Group controlling self & $\begin{array}{l}\text { Consistency and } \\
\text { Continuing } \\
\text { promoting T1-T5 }\end{array}$ & $\begin{array}{l}\text { Randomized } \\
\text { Evaluating health } \\
\text { status of the } \\
\text { conscripts every } 3 \\
\text { months. }\end{array}$ \\
\hline
\end{tabular}

Diagram 1, Conscripts' unconcern with the severity of HIV infection that leads to not perceiving their self efficacy (see Figure 1). Furthermore, they lack supports and have no purpose in their life. These issues influence their risky behaviors and their intention to not change from risky to healthy behaviors. Conscripts who have concern for the severity of HIV infection, but lack perception of self-efficacy, lack supports, and have no purpose in life are also likely to engage in risky behaviors. However, conscripts with concern about the severity of HIV infection who perceive their self-efficacy appear to receive sufficient support, and have purpose in their life. These conscripts change their behaviors from risky to healthy behaviors and intend to continue their healthy behaviors. In The Model, the conscripts who are unconcerned about the severity of HIV infection, and do not perceive self-efficacy will undergo an intervention to promote self-awareness of the 
severity of infection and the consequences of the impact of the disease (T1). The intervention will also enhance their self-efficacy by employing certain strategies for this group (T2). Additionally, adequate supports (T3), and encouraging purposes (T4) in life should be provided for this particular group in order to facilitate them have strong self-efficacy in order to change their risky behaviors to healthy behaviors. Finally, specific intervention should be provided for conscripts to help them continue maintaining healthy behaviors (T5). Based on The Model, development of an activity guideline is shown in Table 5.

\section{Discussion}

\subsection{Health behaviors}

The study finding revealed the majority of the subjects have no to slightly low HIV risky behaviors. This explained by the fact that the subjects may spend most of their time in camp, and did not have opportunities to engage in risky behavior. Camp life involves daily training and a strict schedule, therefore, conscripts were frequently tired and not inclined to seek opportunities to engage in risky behavior. Looking at behaviors related to the risk of HIV infection, it was found that alcohol/drug use had the highest scores, followed by daily living habits, and sexual activities. This finding was consistent with several previous studies which showed that conscript's use of alcohol to relieve stress from training influences their joyfulness, sense of shame, and decision making to engage in unsafe sexual activities ${ }^{[12-14,16,20,27]}$. Most of the subjects' age fall in that period of life when they are most curious and are challenged to try having multiple episodes of sexual intercourse with multiple partners, accompanied by alcohol, smoking and drug use. They believe this is manly behavior. This finding is consistent with the survey of conscripts' life skill ${ }^{[28]}$. In addition, these behaviors have a negative relation to an intention to use condoms ${ }^{[29]}$. The qualitative study finding supported quantitative results that focused on the subjects' behavior using alcohol more than drugs, with alcohol influencing unsafe sexual behaviors. The previous study of Frits ${ }^{[30]}$ supported this finding. The reason that few subjects mentioned their use of drugs may be their reluctance to disclose this issue. Conscripts who engage in drug use are aware that it violates rules of army discipline for which they are likely to be punished. Engaging in alcohol consumption is perceived to be not so serious an issue provided they control their behavior.

\subsection{Motivation for HIV prevention}

The level of motivation for HIV prevention was moderate. This indicated that the conscripts are being mindful of the need to protect themselves from HIV infection. Looking at their motivation we found that perception of severity of the disease had the highest mean scores followed by life-expectation, self-efficacy, and social support. This was congruent with the protection motivation theory which explained that individuals using the first step in the cognitive process, assessing the threat of the severity of HIV/AIDS, and its impact. When individuals feel that a threat is more severe and can impact their health and security, they will consider adjusting their behaviors in ways to protect that noxiousness ${ }^{[24]}$. Several previous studies supported this finding which indicated that the perception of severity of AIDS related to intention to use condoms ${ }^{[22,31]}$. The current study also revealed life-expectation and self-efficacy had mean scores following the perception of severity of the disease. This finding also is supported by the protection motivation theory and Transtheoretical Model: stage of change ${ }^{[32]}$ which explains the next step for individuals after assessing the threat or probability of the threat, and is used to evaluate their coping appraisal. This goes to their self-efficacy to manage the threat. Moreover, it also assesses the outcomes based on whether their responses reflect positive or negative outcomes. In this case, if their response indicated they did not involve themselves in risky HIV behaviors, their life-expectation will be positive \& healthy with likelihood for a good life. Alternatively, if they are still engaging in risky HIV behaviors, their future will be not be good; sickness is likely and they will be a burden on their family. Social support was the last factor involved in helping their decision making to change from risky to healthy behaviors, or to maintain healthy behavior.

The qualitative findings confirmed quantitative findings that the conscripts viewed HIV/AIDS as severe and having more harmful impacts on their health, and also their families. Additionally, they viewed themselves as having sufficient self- 
efficacy to control themselves by not engaging in risky behaviors. Their sense of self-efficacy allowed them to expect a good life in their future, and perceive having adequate support from family, friends, and commanders. For conscripts changing from risky to healthy behaviors, the subjects perceived the severity of HIV/AIDS. However, they were unsure about their self-efficacy to avoid engaging in risky behaviors when they were confronted by friends or other circumstances. However, the subjects desired to have a good life in their future and have good relationships with their families.

For conscripts engaging in risky behaviors, they perceived the severity of HIV/AIDS, but were unconcerned. They are unable to control themselves by avoiding risky behaviors in any situation. They also viewed themselves as a burden on the family, and lacking support. Friends are the most important and influential persons for them. This is explained by the theoretical framework used in the study which indicated concepts in motivation processes are congruent to each other. Not only concerning the severity of the threat, but individuals also are self-confident in their self-efficacy to manage that threat. The appraisal of other supports is necessary to achieve a positive healthy behavior response for preventing HIV infection.

Interestingly, in the conscripts with healthy behaviors show concern about the severity of HIV/AIDS, are able to control themselves, and appear to have good life goals. Thus, social support may be the most important factor that influences them to maintain healthy behaviors. For those alternatively risky to healthy behaviors, it appears this group lacks selfconfidence and self-efficacy in being able to avoid being talked into unhealthy behaviors and pursuing activities in risky environments. Therefore, enhancing their courage, self-efficacy, and continuing to provide adequate supports will promote healthy behaviors for this group. For the risky behaviors group, the important step seems to be recognition of the severity of HIV/AIDS and its impact in order to drive these groups to change their behaviors. If this particular group manages to achieve this first step of recognition, encouraging their self-efficacy, life expectation, and social support intervention will follow. Based on the Trans-theoretical model, the subjects in the risky HIV behavior group are categorized in the Pre-contemplation phase, when a person is not considering change. In the current study the risky behaviors group unconcerned about the risk of HIV infection, and have no motivation to change their behaviors. This group should be strongly encouraged to perceive the severity of HIV/AIDS, and its impacts. The subjects in the second group, alternating from risky to healthy behaviors are categorized in the Contemplate and Preparedness phase. The contemplation is the stage of change that when change is under consideration. Preparedness is the process of preparing to implement a change. Although the subjects in this group have some awareness of the risk of the disease and intention to change, they lack the self-confidence to overcome their negative behaviors. This group should be helped to achieve their self-efficacy while simultaneously continuing to promote the perception of the severity of the disease. Subjects displaying healthy behaviors are categorized as being in the Action phase. Action is when the change is recent but implemented. However, although this group has begun to display healthy behaviors, they need support to continue promotion of selfefficacy, and simultaneously continuing the promotion of external supports to help them maintain their healthy behaviors to the termination phase. The termination phase consists of those conscripts who have been able to completely maintain their healthy behaviors necessary to permanently avoid HIV/AIDS. Social supports are to be promoted through all phases of the subjects.

\subsection{Factors related to protection motivation}

The correlation between selected factors and motivation in preventing HIV infection, revealed an overall positive significant relationship among the availability of being able to consult a wife, girlfriend, close friend, or parents when having stress, having a hobby, experience viewing AIDS patients, army policy, the influence of a commander, proximity to their home town, and character of army training. Forward regression analysis was conducted to explore the predictor of motivation for preventing HIV infection. The analysis showed the above factors account for $7 \%$ of the variance of motivation for preventing HIV infection. Social support seems to be the most influential factor enhancing protection motivation. The availability of loved ones or close friends when they have stress influences their protection motivation. This is consistent with the qualitative findings that subjects in the healthy group perceived they had adequate supports. Experience viewing AIDS patients was another factor that influenced protection motivation. The conscripts who had this 
experience may recognize the severity and the impact of the disease. This is also congruent with qualitative finding that indicated the subjects alternating from risky to healthy behaviors had experience with direct and indirect viewing of AIDS patients leading to more awareness of the impact of the disease. Influence of commanders and army policy were other factors associated with protection motivation. The army's policies focus on personnel health, promotion of knowledge about the severity of AIDS, disease prevention by providing HIV/AIDS education programs along with sports and hobby programs, and peer education. These programs enhance the conscripts' opportunities to avoid risky behaviors. Several previous studies reported that risky behaviors of conscripts decreased after participating in these programs ${ }^{[33]}$. However, having a hobby was not one of the selected factors in this study, but found to be one of the predictors of protection motivation. This may explain that having a hobby while in the army, such as planting a garden or farming may lead to greater income for conscripts and substantially limit their time to join in alcohol drinking or going to the brothel.

\section{I mplications}

The study findings will help army commanders better understand the protection motivation process and related factors affecting conscripts. Therefore, the study will provide a good opportunity for the military sector to take part in the development of HIV/AIDS policies, and the establishment of military strategies and interventions that promote healthy behavior or prevent risky behavior in each step of the model of HIV prevention developed by this study. This will impact the specific groups of conscripts appropriately and effectively. The model will provide guidance on how to best impact each groups' behavior in each step of motivation leading to a better quality of life for army personnel and their families, and increase the capacity of military personnel and security of the country.

\section{Recommendations for further research}

Further research should be conducted to compare the health behaviors of the conscripts before and after application of the Model for preventing HIV infection. The research will explore factors associated with the behaviors of each group of conscripts, and test the effectiveness of the model after intervention.

\section{References}

[1] UNAIDS. 'Unite for universal access: Overview brochure on 2011 High Level Meeting on AIDS: Geneva. 2010.

[2] UNAIDS. Report on the global AIDS epidemic. 2007.

[3] National AIDS Prevention and Alleviation Committee. UNGASS Country Progress Report Thailand. 2010: Available from: http://www.avert.org/thailand-aids-hiv.htm (4 May 2012 date last accessed)

[4] WHO, UNAIDS, \& UNICEF. Global HIV/AIDS Response: Epidemic update and health sector progress towards universal access. Geneva. 2011.

[5] UNAIDS. Report on the global AIDS epidemic. Geneva: 31-33. 2008.

[6] Kaiser Family Foundation. National Survey of Teens on HIV/AIDS. 2000.

[7] Shephard, R.J., \& Shek, P.N. Immune dysfunction as a factor in heat illness. Crit Rev Immunol. 2000; 19: 285-302.

[8] Adebayo, S.B, Mafeni, J., Moreland, S., \& Murray, N. Knowledge, attitude and sexual behavior among the Nigerian military concerning HIV/AIDS and STDs. Armed forces programme on AIDS control (AFPAC). Final Technical Report. 2002; September: 95.

[9] Bing E.G., et al. HIV/AIDS behavioral surveillance among Angolan military men. AIDS and Behavior. 2007; 12: 578-584. PMid:17641966 http://dx.doi.org/10.1007/s10461-007-9280-1

[10] Fleming D.T, Wasserheit, J.N. From epidemiological synergy to public health policy and practice: the contribution of other sexually transmitted diseases to sexual transmission of HIV infection. Sexually Transmitted Infections. 1999; 75:3-17. http://dx.doi.org/10.1136/sti.75.1.3

[11] Jenkins, R. A., Jenkins, P.R., Nannis, E.D., Mckee, K.T., \& Temoshok, L.R. Correlates of human immunodeficiency virus infection risk behavior in male attendees of a clinic for sexually transmitted diseases. Clinical Infectious Diseases. 2000; 30: 723729. PMid:10770735 http://dx.doi.org/10.1086/313744 
[12] Celentano, D.D., Nelson, K.E., Suprasert, S., Wright, N., Manasarawoo, A., Eiumtrakul, S., et al. Behavioral and sociodermographic risks for frequent visits to commercial sex workers among northern Thai men. AIDS. 1993; 7: 1647-52. PMid:8286075 http://dx.doi.org/10.1097/00002030-199312000-00016

[13] Bhusal, B.K. Assessment of sexual risk behavior regarding HIV/AIDS infection among Royal Thai army conscripts in Bangkok, Thailand. Dissertation: Mahidol University. 2001.

[14] Akwir, M., Arkangel, A., Moluma, D., Idro, J.W., Homsy, J. Vulnerability of refugee women to HIV/AIDS infection in refugee camps in northern Uganda. In Proceeding of the XII world AIDS conference, June 1998: Geneva. 2002; Retrieved in Hankins, C.A.

[15] Semple, S.J., Patterson, T.L., \& Grant, I. Determinants of condom use stage of change among heterosexually identified methamphetamine users. AIDS and Behavior. 2004; 8: 391-400. PMid:15690112 http://dx.doi.org/10.1007/s10461-004-7323-4

[16] Hla, T.O. Safe sex behaviors among conscripts in Royal Thai Army, Southern Thailand. Dissertation, Mahidol University. 1999.

[17] Cheawprom, N. General Psychology. 2003. Available from: http://courseware.rmutl.ac.th/courses/43/unit1101.htm (5 February 2012 date last accessed)

[18] Coovadia H. Access to voluntary counseling and testing for HIV in developing countries. Annals of the New York Academy of Science. 2000; 918: 57-63. http://dx.doi.org/10.1111/j.1749-6632.2000.tb05474.x

[19] Leonard, L., Ndiaye, I., Kapadia, A., Eisen, G., Diop, O., Mboup, S., et al. HIV prevention among male clients of female sex workers in Kaolack, Senegal: results of a peer education program. AIDS Education and Prevention. 2000; 12: $21-37$. PMid:10749384

[20] Meesiri, S., et al. Data for HIV Policy, Planning, Program, and Strategy Management. Asia Pacific/South Asia HIV/AIDS Policy Workshop, Bangkok, Thailand, Annual Report 2004. 7-10 September 2004.

[21] Kapiga, S.H., Lwihula, G.K., Shao, J.F., \& Hunter, D.J. Predictors of AIDS knowledge, condom use and high-risk sexual behavior among women in Dar-es-Salaam, Tanzania. Int J STD AIDS. 1995; 6: 175-183. PMid:7647120

[22] Mbizvo, M.T., Ray, S., Bassett, M., McFarland, W., Machekano, R. \& Katzenstein, D. Condom use and the risk of HIV infection: Who is being protected? Cent Afr J Med. 1994; 40: 294-299. PMid:7859268

[23] Okulate, G.T., Jones, O.B., \& Olorunda, M.B. Condom use and other HIV risk issues among Nigeria soldiers: challenges for identifying peer educators. AIDS Care. 2008; 20 (8): 911-916. PMid:18777219 http://dx.doi.org/10.1080/09540120701777264

[24] Rogers, R. W. Cognitive and physiological processes in fear appeals and attitude change: A revised theory of protection motivation. In J. T. Cacioppo \& R. E. Petty (Eds.), Social psychophysiology: A sourcebook (pp. 153-176). New York: Guilford. 1983.

[25] Prochaska, J. O., \& DiClemente, C.C. The transtheoretical approach: In J.C. Norcross (Ed.) Handbook of eclectic psychotherapy (pp. 163-200). New York: Plenum. 1986.

[26] Johnson, L.J., \& LaMontague, M. J. Research methods using content analysis to examine the verbal or written communication of stakeholders within early intervention, Journal of Early Intervention. 1993; 17(1): 73-79.

http://dx.doi.org/10.1177/105381519301700108

[27] Asavikul, P. Biostatistical methods on HIV infection among Thai military conscripts. Master of Science Thesis. Mahidol University, Nakhon Pathom. 2007.

[28] Pumsanyaong, K., Prasitivaichakul, A, \& Prachunkeit, A. Stress and Life Skills in Thai Army Conscripts. The Royal Thai Army Nursing College. 2010.

[29] Ekere, J.E., Gbadebo, O.O., Harrison, N. K., Ernest, E., Doriel, W., \& Laurens, H. Emerging socio-demographic and lifestyle predictors of intention to use condom in Human Immunodeficiency Virus (HIV) intervention among Uniformed Services Personnel. Military Medicine. 2006; 171(10): 1027-1034

[30] Frits, V., Thanprasertsuk, S., Jommaroeng, R., Mansergh, G., Naorat, S., Jenkins, R., et al. Evidence of previously undocumented epidemic of HIV infection among men who have sex with men in Bangkok, Thailand. Epidemic and Social: Concise Communication. 2005; 19(5): 521-526.

[31] Lugoe, W.L., Klepp, K.I., \& Skutle, A. Sexual debut and predictors of condom use among secondary school students in Arusha, Tanzania. AIDS Care. 1996; 8: 443-452. PMid:8863915 http://dx.doi.org/10.1080/09540129650125632

[32] DiClemente, C.C., \& Prochaska, J.O. Self-change and therapy change of smoking behavior: a comparison of processes of change of cessation and maintenance. Additive Behaviors. 1982; 7: 131-142. http://dx.doi.org/10.1016/0306-4603(82)90038-7

[33] Brook, C., Apeagyei, F., Gomez, B., Baez, E., Payapvipong, P., Fraser-MacKenzie, P., et al. AIDS Prevention Programs for Men: Workplace Interventions in Developing Countries. Paper presented at the 120th Annual meeting of the American Public Health Association, Washington DC, 8-12 November. 1994. 